\title{
SISTEM INFORMASI MANAJEMEN PROYEK BERBASIS KANBAN (STUDI KASUS: PT. XYZ)
}

\author{
Agung Sirajuddin Vidianto*1, Wachyu Hari Haji² \\ 1,2 Universitas Mercu Buana \\ Email: ${ }^{1}$ agung.sirajuddin@gmail.com, ${ }^{2}$ wahyuhari@mercubuana.ac.id \\ *Penulis Korespondensi
}

(Naskah masuk: 21 Januari 2019, diterima untuk diterbitkan: 06 Februari 2020)

\begin{abstract}
Abstrak
Penelitian ini mengkaji mengenai permasalahan yang terjadi ketika sebuah perusahaan mengerjakan sebuah proyek. Banyak perusahaan menghadapi kesulitan dalam mengelola proyek, menyediakan informasi, dan memberikan hasil proyek yang berkualitas, hal tersebut sering kali terjadi bukan karena kurangnya sumber daya maupun kurang handal-nya SDM yang digunakan, namun lebih kepada sulitnya menentukan, merencanakan, dan melacak perkembangan proyek tersebut. Penelitian ini menggunakan studi kasus pada PT. XYZ, dimana perusahaan tersebut tidak memiliki sistem informasi manajemen proyek dan hanya mengandalkan program berbasis desktop untuk mengelola proyek yang ada, sehingga terdapat kesulitan dalam pengelolaan proyek dari segi berbagi informasi, manajemen sumber daya, dan manajemen waktu. Sehingga diperlukannya sebuah sistem manajemen proyek untuk mempermudah pengelolaan kegiatan proyek yang ada di PT. XYZ. Dengan menggunakan teknologi informasi, maka dibuatlah sebuah sistem manajemen proyek berbasis kanban, yang berfungsi memonitor perkembangan dan tingkat penyelesaian proyek, mempermudah pengelolaan sumber daya dan tugas, serta menyediakan laporan dari proyek yang ada.
\end{abstract}

Kata kunci: kanban, scrum, sistem manajemen proyek

\section{KANBAN BASED PROJECT MANAGEMENT INFORMATION SYSTEM (CASE STUDY: PT. XYZ)}

\begin{abstract}
This study examines the problems that occur when a company is working on a project. Many companies face difficulties in managing projects, providing information, and providing quality project results, this often happens not because of lack of resources or lack of reliable HR used, but more difficult to determine, plan, and track the progress of the project. This study uses a case study at PT. XYZ, where the company does not have a project management information system and only relies on desktop-based programs to manage existing projects, so there are difficulties in project management in terms of information sharing, resource management, and time management. So the need for a project management system to facilitate the management of existing project activities at PT. XYZ. By using information technology, a kanban-based project management system is created, which functions to monitor the progress and level of project completion, facilitate management of resources and tasks, and provide reports of existing projects.
\end{abstract}

Keywords: kanban, scrum, project management system

\section{PENDAHULUAN}

Peranan komputer pada saat ini sangatlah besar dalam segala bidang, baik bidang bisnis, hiburan, hingga militer. Dengan adanya komputer dapat mempermudah dan mempercepat suatu pekerjaan, menjalankan proses yang rumit, dan automisasi suatu kegiatan. Dari kegiatan dalam sebuah instansi, salah satunya adalah adanya proyek. Tantangan utama sebuah proyek adalah mencapai sasaran-sasaran dan tujuan proyek dengan menyadari adanya batasan ruang lingkup pekerjaan, waktu dan pembagian pekerjaan dan anggaran pekerjaan.

Berdasarkan Project Management Body of Knowledge, terdapat 6 buah konstrain dalam sebuah proyek, yaitu waktu (time), biaya (cost), ruang lingkup (scope), kualitas (quality), sumber daya (resource), dan resiko (risk) (A Guide to the Project Management Body of Knowledge, 2013). Dalam proyek, satu atau lebih dari konstrain tersebut dapat memiliki beban atau nilai yang lebih besar dari 
konstrain lainnya, dan seorang manajer proyek harus dapat menyeimbangkan konstrain-konstrain tersebut dengan cara yang dapat mencapai semua tujuan dari proyek (Mahmoudi \& Feylizadeh, 2017).

Sebagai contoh dalam konstrain waktu dan sumber daya. Pembagian porsi pekerjaan harus sesuai dengan beban pekerjaan dan jadwal pekerjaan tersebut selesai, sehingga membutuhkan seorang manajer proyek yang sangat mengerti kondisi lapangan, yang dapat memilih orang yang tepat dan pekerjaan yang tepat. Sistem manajemen proyek dapat membantu tugas dari manajer proyek tersebut dengan menampilkan informasi jadwal pekerjaan, daftar anggota tim, dan tingkat performa anggota tim, sehingga seorang manajer proyek dapat lebih efisien dalam mengelola sumber daya dan waktu yang dimiliki.

Dengan adanya tantangan dan batasan-batasan tersebut, maka perlu adanya solusi sebuah sistem manajemen yang dapat membantu mengelola data, biaya, progress, dan jadwal sebuah proyek secara sistematis dan baik. Sistem manajemen proyek dapat membantu dalam proses pengolahan dan penyimpanan data sehingga dapat terpusat, terstruktur, dan lebih terbuka.

Penelitian ini bertujuan untuk mengembangkan sistem informasi manajemen proyek dimana bertujuan untuk membantu manajer proyek dalam mengelola konstrain-konstrain proyek, dengan menggunakan data dari hasil studi kasus pada PT. XYZ dan dengan menggunakan hasil penelitianpenelitian pada bidang manajemen proyek yang sudah ada.

PT. XYZ sendiri merupakan sebuah perusahaan manufaktur peralatan rumah tangga yang didirikan pada tahun 1997, dan mempunyai produk utama yaitu kotak makan dan botol minum plastik dengan gambar tokoh kartun atau tokoh superhero berlisensi. Hal ini membuat PT. XYZ membutuhkan staf desain yang harus bekerja untuk mendesain bentuk produk dan bagaimana desain gambar decal atau stiker pada produk nantinya, dimana biasanya tokoh yang digunakan mengikuti tren saat itu. Sehingga dapat dikatakan setiap terdapat tren baru yang muncul, maka akan terdapat proyek desain yang harus diselesaikan segera sebelum tren tersebut hilang.

Selain desain, PT. XYZ juga memiliki bagian TI yang berfungsi untuk meningkatkan produktifitas dan efisiensi perusahaan dengan menggunakan teknologi informasi. Setiap kegiatan pada bagian TI biasanya akan menyangkut banyak pihak dan memiliki deadline yang ketat, baik ketika melakukan peningkatan kinerja, perbaikan sistem, maupun pembaharuan sistem. Sehingga diperlukannya sebuah sistem manajemen proyek untuk mempermudah pengelolaan kegiatan proyek yang ada di PT. XYZ.

PT. XYZ sendiri telah menggunakan beberapa tools untuk mengelola proyek yang dikerjakan, namun sistem tersebut masih berbasis desktop, sehingga sulit dalam berbagi informasi. Selain itu, seringnya satu orang staf memegang lebih dari satu proyek juga mempersulit manajer proyek dalam melacak kegiatan staf tersebut, sehingga sering kali terjadi proyek tidak selesai tepat waktu, beban staf yang berat, dan tidak sinkron-nya data staf dengan manajer proyek. Maka dari itu, penelitian ini diharapkan dapat menghasilkan suatu sistem manajemen proyek yang berbasis web sehingga lebih mudah untuk diakses dan lebih mudah dikelola.

Penggunaan kanban sebagai basis dasar sistem didasarkan dari penggunaan board dan task pada kanban. Dengan sistem berbasis board dan task, selain pengguna dapat mengelola proyek dan kegiatan dengan lebih mudah, juga lebih familiar dikarenakan budaya pada lokasi studi kasus dimana staf departemen menggunakan sistem task dan selfassign untuk kegiatan sehari-hari, sehingga dengan menggunakan basis kanban, pengguna dapat lebih familiar dengan sistem yang akan dikembangkan.

Dengan berdasarkan penelitian-penelitan sebelumnya dan hasil studi kasus pada PT. XYZ, penelitian ini diharapkan dapat menghasilkan sebuah sistem manajemen proyek yang sesuai dengan kebutuhan dari hasil studi kasus dengan tetap menjaga kesederhanaan sistem.

\section{METODE PENELITIAN}

Penelitian ini adalah penelitian studi kasus, dengan mengangkat kasus pengembangan sistem informasi manajemen proyek pada PT. XYZ. Metode pengumpulan data yang digunakan adalah dengan metode wawancara, studi dokumentasi, dan studi penelitian sebelumnya. Pengumpulan data dilakukan pada tanggal 5 November 2018.

Narasumber yang diwawancarai adalah Supervisor divisi ICT, staf divisi ICT, dan staf divisi desain grafis pada PT. XYZ. Narasumber berfungsi sebagai sumber data dan informasi bagaimana pengelolaan proyek yang digunakan. Selain itu, narasumber juga berfungsi sebagai sumber data dan informasi kebutuhan sistem dan sebagai penguji sistem akan dikembangkan.

Dokumen yang digunakan dalam studi dokumentasi merupakan dokumentasi dari proyek yang telah lalu, dokumentasi proyek berjalan, dan dokumentasi manajemen kegiatan sehari-hari. Dokumen berfungsi sebagai dasar dalam pembuatan basis data, laporan, dan kebutuhan dalam pengembangan sistem.

Pengembangan sistem informasi pada penelitian ini menggunakan pendekatan Agile Development Cycle dengan metode pengembangan berbasis SCRUM.

Alur penelitian meliputi perumusan masalah, penentuan tujuan, studi pustaka, pengumpulan data, analisa dan perancangan kebutuhan sistem dimana didalamnya terdapat perancangan basis data dan perancangan tampilan antar muka, kemudian dilakukan perancangan program dan implementasi, 
dan diakhiri dengan kesimpulan dan saran. Alur penelitian dapat dilihat pada Gambar 1 .

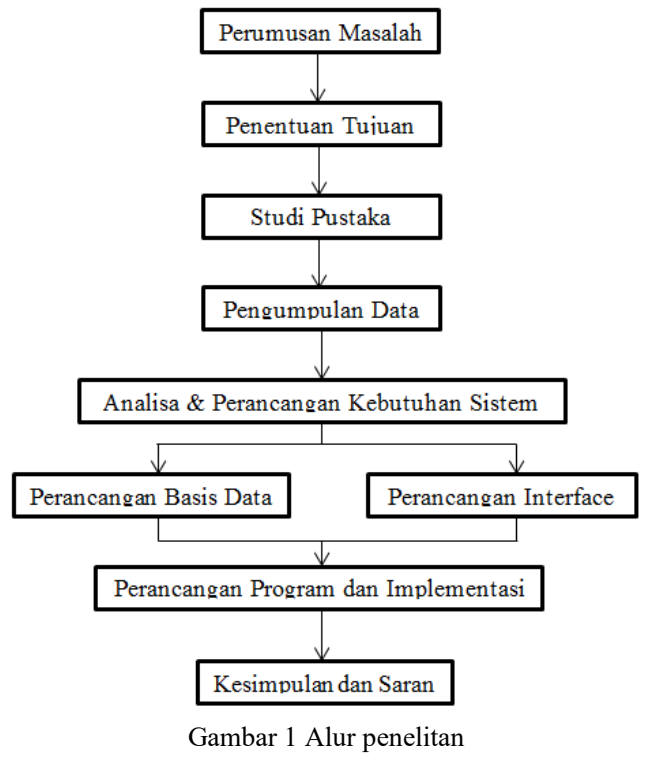

\section{PERANCANGAN SISTEM}

\subsection{Tinjauan Pustaka}

\subsubsection{Manajemen Proyek}

Manajemen Proyek merupakan proses dari perencanaan, penjadwalan, pengelolaan sumber daya, analisa kebutuhan, perancangan, dan pengujian untuk mencapai tujuan dan sasaran proyek. Tanpa manajemen proyek, akan sulit untuk menyelesaikan proyek dalam waktu yang diberikan. Sehingga dibutuhkan manajemen proyek untuk menghilangkan batasan dan rintangan yang ada dalam pengem bangan proyek dan untuk mencapai tujuan proyek (Kale, Shewale, Sarang, Pawar, \& Sadruddin, 2017).

Tujuan dari manajemen proyek adalah untuk dapat mengelola fungsi manajemen dalam sebuah proyek sehingga dapat diperoleh hasil yang optimal sesuai dengan persyaratan yang ada dan telah ditetapkan serta untuk dapat mengelola sumber daya yang efisien dan efektif (Padma Arianie \& Budi Puspitasari, 2017).

\subsubsection{Kanban}

Kanban merupakan sistem alur kerja yang biasa digunakan dalam proses manufaktur dan pengembangan perangkat lunak untuk meningkatkan efisiensi dan produktivitas. Namun kanban juga dapat digunakan dengan efektivitas yang sama untuk menjaga segala bentuk proyek agar tetap pada jalurnya atau sebagai alat untuk manajemen waktu pribadi. Kanban dikembangkan pertama kali pada akhir tahun 1940 oleh Toyota untuk mempersingkat dan mendukung proses manufaktur yang "tepat sebelum deadline", metodologi kanban kemudian diadopsi oleh David Anderson sebagai sebuah alat dalam metodologi Agile (Graham, 2017).

Pada intinya, kanban merupakan sistem yang memvisualisasikan perkerjaan. Inti dari metodologi kanban adalah pembuatan "board" dimana kita meletakkan "card" atau kartu yang berisi tugas yang perlu diselesaikan. Dalam bentuk paling sederhana, sebuah Kanban Board berisi tiga kolom: yang perlu dikerjakan, yang sedang dikerjakan, yang telah dikerjakan (Graham, 2017).

Juga inti dari metodologi kanban adalah konsep membatasi jumlah pekerjaan yang sedang dikerjakan agar perhatian dan kerja tim lebih terfokus, sehingga membatasi jumlah waktu yang dibutuhkan untuk menyelesaikan tugas yang dipindahkan ke kolom tugas yang telah dikerjakan dan membantu memperlihatkan potensi-potensi kemacetan beban kerja (Graham, 2017).

\subsubsection{SCRUM}

SCRUM merupakan sebuah proses manajemen dan kontrol yang digunakan untuk mengembangkan dan menopang produk yang kompleks untuk membangun perangkan lunak yang memenuhi kebutuhan bisnis, secara incremental dan secara empiris. SCRUM dianggap sebagai sebuah metode agile yang banyak digunakan, pertama kali dideskripsikan pada tahun 1996. SCRUM juga dianggap metode yang ringan, mudah dimengerti, dan susah untuk dikuasai (Al-Zewairi, Biltawi, Etaiwi, \& Shaout, 2000).

SCRUM dimulai dengan memecah proyek menjadi iterasi (sprints). Sebelum setiap sprint, dalam tahap perencanaan, semua tugas yang perlu diselesaikan disimpan dalam sebuah daftar bernama "release backlog". Dalam proses perencanaan, tujuan sprint selanjutnya diidentifikasi dan diumumkan kepada pengembang dengan tujuan untuk menunjukkan kepada mereka tugas-tugas apa yang sedang dilakukan dan pada tingkat detil mana untuk mengimplementasikannya, sebagai tambahan, kumpulan tugas prioritas dipilih dari release backlog untuk diselesaikan pada sprint selanjutnya. Ketika tahap perencanaan selesai, setiap tim pengembangan sudah membawa tugas-tugas masing-masing (AlZewairi, Biltawi, Etaiwi, \& Shaout, 2000).

Tugas-tugas pada sprint backlog tetap tidak berubah hingga fase sprint berakhir. Ketika tim pengembangan mengembangkan tugas-tugas mereka, proyek harus di lacak dan dipantau melalui pertemuan harian dan melacak status tugas untuk meningkatkan komunikasi antar tim, dan agar tim tetap fokus pada sasaran proyek secara keseluruhan. Setelah setiap sprint, proses analisa dan evaluasi berlangsung melalui pertemuan pre-sprint (Al-Zewairi, Biltawi, Etaiwi, \& Shaout, 2000).

\subsubsection{Penelitian Terkait}

Terdapat beberapa penelitian yang telah dilakukan sebelumnya mengenai sistem manajemen proyek, dimana salah satunya adalah peneliatan yang 
dilakukan oleh Aaron. A. Izang, Chinyere. C. Ihesiulo, Miracle Ofuru, dan Chukwuebuka Okafor dengan judul "A Web-Based Project Management System". Penelitian ini menghasilkan sebuah sistem manajemen proyek berbasis web dimana data proyek dapat diinput kedalam sebuah sistem dan dikelola secara terpusat dan terstruktur (Izang, Ihesiulo, \& Okafor, 2016).

Penelitian yang kedua dilakukan oleh Sanket Kale, Aniket Shewale, Premsagar J. Sarang, Prasad S.Pawar, dan Safia Sadruddin dengan judul "Project Management System (PMS)". Penelitian ini menghasilkan sebuah sistem informasi manajemen proyek yang berfokus pada manajemen ketiatan pada setiap langkah atau tingkat proyek (Kale, Shewale, Sarang, Pawar, \& Sadruddin, 2017).

Penelititian yang ketiga dilakukan oleh Junar A. Landicho dengan judul " $A$ web-based geographical project monitoring and information system for the road and highways". Penelitian ini menghasilkan sistem informasi manajemen proyek dimana berfungsi sebagai sistem monitoring dari proyek pengerjaan jalan dengan menggunakan API Google Maps (Landicho, 2018).

Penelitian yang keempat dilakukan oleh Heru Setiawan, M. dan Qadafi Khairuzzaman dengan judul "Perancangan Sistem Informasi Manajemen Proyek : Sistem Informasi Kontraktor". Penelitian ini menghasilkan sebuah sistem informasi manajemen proyek yang berfokus pada manajemen dokumen dan perizinan (Setiawan \& Khairuzzaman, 2017).

Penelitian yang kelima dilakukan oleh Puar Z dan Siregar $M$ dengan judul "Rancangan Sistem Elektronik Kanban Untuk Meningkatkan Efektivitas Produksi Just In Time". Penelitian ini menghasilkan sebuah sistem E-Kanban yang merupakan hasil transformasi dari sistem kanban manual yang sudah ada (Puar \& Siregar, 2017).

Penelitian yang keenam dilakukan oleh Houti M, El Abbadi L, dan Abouabdellah A dengan judul" E-Kanban The New Generation Of Traditional Kanban System, And The Impact Of Its Implementation In The Enterprise". Penelitian ini menghasilkan perbandingan dari penggunaan sistem kanban tradisional dengan E-Kanban (Houti, El Abbadi, \& Abouabdellah, 2017).

Perbandingan penelitian ini dengan keenam penelitian sebelumnya adalah kebutuhan dari penggunaan sistem informasi manajemen proyek. Aplikasi pada penelitian pertama tidak memiliki menu manajemen pengeluaran dan manajemen dokumen sehingga kedua hal tersebut masih harus dikelola secara manual. Aplikasi pada penelitian kedua lebih berfokus sebagai wadah hasil tugas dan kegiatan yang telah dilakukan dengan model akses satu sistem satu admin. Aplikasi pada penelitian ketiga lebih berfokus sebagai aplikasi monitoring kegiatan lapangan dengan sumber masukan data dari satu admin, dengan pengguna lain hanya dapat melihat status proyek. Aplikasi pada penelitian keempat lebih berbentuk sebagai sistem manajemen adminstrasi untuk mengelola dokumen dan perizinan. Pada penelitian kelima menghasilkan sistem EKanban yang berdasarkan pada sistem kanban tradisional yang sudah ada. Dan pada penelitian keenam merupakan penelitian yang menghasilkan informasi mengenai kelebihan dari E-Kanban yang digunakan sebagai salah satu dasar pemilihan kanban sebagai basis pengembangan sistem pada penelitian ini.

Kebutuhan dari sistem manajemen proyek pada penelitian ini lebih kepada dinamisnya interaksi antar anggota tim proyek sehingga setiap anggota tim dapat mengelola proyek dan tugas yang dijalankannya masing-masing secara langsung tanpa perlu melalui admin proyek.

\subsection{Analisa Proses Bisnis Berjalan}

Pengelolaan proyek pada PT XYZ saat ini masih secara manual dimana pengelolaan kegiatan dan progress proyek menggunakan Microsoft Excel yang dibuat oleh pemimpin proyek. Adapun proses bisnis manajemen proyek yang terjadi pada PT. XYZ sebagai berikut:

1) Project Manager mendefinisikan proyek yang akan dikerjakan.

2) Project Manager melakukan cross-check dengan pihak terkait mengenai dokumen definisi proyek.

3) Apabila dokumen definisi proyek disetujui, maka Project Manager kemudian memilih anggota tim proyek dan Project Leader.

4) Tim proyek memulai pengumpulan data-data requirement proyek.

5) Tim proyek melakukan analisa dan menghasilkan rencana dan desain proyek.

6) Tim proyek melakukan pengerjaan tugastugas yang dibagikan oleh Project Leader.

7) Tim proyek melakukan pengujian dari dalam dan pihak-pihak terkait melakukan pengujian dari luar.

8) Apabila hasil uji lolos maka dilakukan penyerahan hasil proyek.

9) Tim proyek dan pihak terkait melakukan review hasil pengerjaan proyek.

10) Proyek ditutup dan dinyatakan selesai.

\subsection{Analisa PIECES}

\begin{tabular}{|c|c|c|}
\hline Parameter & Kendala & Solusi \\
\hline Performance & $\begin{array}{ll}\text { a. } & \text { Semua } \\
\text { pencatatan } \\
\text { dan } \\
\text { pengelolaan } \\
\text { dilakukan }\end{array}$ & $\begin{array}{l}\text { a. Setiap anggota } \\
\text { proyek akan } \\
\text { dapat } \\
\text { mengelola } \\
\text { kegiatan }\end{array}$ \\
\hline
\end{tabular}


Vidianto \& Haji, Sistem Informasi Manajemen Proyek ... 287

\begin{tabular}{|c|c|c|}
\hline Parameter & Kendala & Solusi \\
\hline & $\begin{array}{l}\text { manual oleh } \\
\text { manajer } \\
\text { proyek dan } \\
\text { tidak dapat } \\
\text { dilakukan } \\
\text { monitoring } \\
\text { oleh anggota } \\
\text { tim proyek } \\
\text { lainnya } \\
\text { selama file } \\
\text { tidak } \\
\text { dibagikan } \\
\text { atau tidak } \\
\text { diperlihatkan } \\
\text { oleh manajer } \\
\text { proyek. } \\
\text { Anggota tim } \\
\text { proyek harus } \\
\text { melakukan } \\
\text { pelaporan } \\
\text { secara manual } \\
\text { kepada } \\
\text { manajer } \\
\text { proyek untuk } \\
\text { didata } \\
\text { progress dari } \\
\text { tugas yang } \\
\text { didapat. }\end{array}$ & $\begin{array}{l}\text { mereka dan } \\
\text { memonitor } \\
\text { progress } \\
\text { proyek secara } \\
\text { mandiri. } \\
\text { b. Setiap anggota } \\
\text { tim proyek } \\
\text { dapat } \\
\text { melakukan } \\
\text { pembaruan } \\
\text { status kegiatan } \\
\text { secara } \\
\text { langsung di } \\
\text { dalam sistem } \\
\text { tanpa harus } \\
\text { menghubungi } \\
\text { manajer } \\
\text { proyek. }\end{array}$ \\
\hline Information & $\begin{array}{l}\text { a. Semua data } \\
\text { harus } \\
\text { dimasukkan } \\
\text { kedalam file } \\
\text { excel secara } \\
\text { manual oleh } \\
\text { manajer } \\
\text { proyek } \\
\text { sehingga } \\
\text { tidak } \\
\text { realtime. } \\
\text { Belum adanya } \\
\text { sistem untuk } \\
\text { menghasilkan } \\
\text { laporan secara } \\
\text { otomatis. }\end{array}$ & $\begin{array}{l}\text { a. Beberapa data } \\
\text { seperti } \\
\text { progress } \\
\text { kegiatan dan } \\
\text { pengeluaran } \\
\text { dapat } \\
\text { dimasukkan } \\
\text { oleh anggota } \\
\text { tim proyek } \\
\text { masing-masing } \\
\text { sehingga data } \\
\text { lebih bersifat } \\
\text { realtime. } \\
\text { b. Sistem yang } \\
\text { dibuat akan } \\
\text { dapat } \\
\text { menghasilkan } \\
\text { beberapa jenis } \\
\text { laporan sesuai } \\
\text { dengan } \\
\text { kebutuhan } \\
\text { pelaporan } \\
\text { proyek. }\end{array}$ \\
\hline Economy & $\begin{array}{l}\text { Semakin } \\
\text { banyaknya tugas } \\
\text { dan waktu yang } \\
\text { terbuang untuk } \\
\text { kebutuhan } \\
\text { administrasi data } \\
\text { dari anggota tim } \\
\text { proyek ke manajer } \\
\text { proyek secara } \\
\text { manual dapat } \\
\text { meningkatkan } \\
\text { biaya SDM. }\end{array}$ & $\begin{array}{l}\text { Tugas dan waktu } \\
\text { dapat dikurangi } \\
\text { dengan adanya } \\
\text { sistem manajemen } \\
\text { proyek dimana } \\
\text { semua data dapat } \\
\text { dimasukkan } \\
\text { secara masing- } \\
\text { masing dan kapan } \\
\text { saja sehingga } \\
\text { mengurangi beban } \\
\text { tugas dan waktu } \\
\text { yang digunakan } \\
\text { oleh manajer } \\
\text { proyek. }\end{array}$ \\
\hline
\end{tabular}

\begin{tabular}{|c|c|c|}
\hline Parameter & Kendala & Solusi \\
\hline Control & $\begin{array}{l}\text { Belum adanya } \\
\text { pengontrolan yang } \\
\text { dapat mem- } \\
\text { validasi data-data } \\
\text { proyek yang } \\
\text { masuk, sehingga } \\
\text { masih harus dicek } \\
\text { secara manual } \\
\text { oleh manajer } \\
\text { proyek dan rentan } \\
\text { terhadap } \\
\text { kesalahan data. }\end{array}$ & $\begin{array}{l}\text { Data yang masuk } \\
\text { ke system semua } \\
\text { akan dapat } \\
\text { terkontrol dan } \\
\text { tersandarisasi jika } \\
\text { mengimplementas } \\
\text { ikan sistem } \\
\text { manajeme proyek. }\end{array}$ \\
\hline Efficiency & $\begin{array}{l}\text { Laporan hanya } \\
\text { dapat dihasilkan } \\
\text { oleh manajer } \\
\text { proyek secara } \\
\text { manual dan harus } \\
\text { dilakukan } \\
\text { pengolahan ulang } \\
\text { data untuk } \\
\text { menghasilkan } \\
\text { laporan yang } \\
\text { berbeda }\end{array}$ & $\begin{array}{l}\text { Perlunya sebuah } \\
\text { sistem yang dapat } \\
\text { menghasilkan } \\
\text { laporan dalam } \\
\text { berbagai bentuk } \\
\text { dan jenis secara } \\
\text { cepat dan } \\
\text { sederhana. }\end{array}$ \\
\hline Service & $\begin{array}{l}\text { a. Anggota tim } \\
\text { proyek tidak } \\
\text { dapat melihat } \\
\text { secara } \\
\text { langsung } \\
\text { progress } \\
\text { kegiatan } \\
\text { diluar } \\
\text { kegiatan yang } \\
\text { ditugaskan } \\
\text { kepadannya. } \\
\text { Pelaporan } \\
\text { kendala, } \\
\text { progress } \\
\text { kegiatan, dan } \\
\text { catatan } \\
\text { pengeluaran } \\
\text { masih } \\
\text { dilakukan } \\
\text { manual oleh } \\
\text { manajer } \\
\text { proyek }\end{array}$ & $\begin{array}{l}\text { a. Disediakannya } \\
\text { sebuah menu } \\
\text { dalam sistem } \\
\text { dimana seluruh } \\
\text { anggota tim } \\
\text { proyek dapat } \\
\text { melihat semua } \\
\text { kegiatan dan } \\
\text { progress dari } \\
\text { proyek yang } \\
\text { mereka } \\
\text { kerjakan. } \\
\text { b. Disediakannya } \\
\text { fitur dalam } \\
\text { sistem untuk } \\
\text { menambahkan } \\
\text { catatan ke } \\
\text { dalam } \\
\text { kegiatan, } \\
\text { pembaruan } \\
\text { status kegiatan, } \\
\text { dan menu } \\
\text { untuk } \\
\text { melakukan } \\
\text { pencatatan } \\
\text { pengeluaran. }\end{array}$ \\
\hline
\end{tabular}

\subsection{Kebutuhan Fungsional}

Berdasarkan dari hasil analisa data dan studi pustaka yang terkumpul, maka dirumuskan lah kebutuhan fungsional sistem sebagai berikut:

1) Semua pengguna dapat membuat proyek.

2) Hanya Project Manager atau Project Leader yang dapat mengelola anggota tim.

3) Project Manager dapat mengelola semua data pengguna.

4) Project Leader dan Agent hanya dapat mengelola data profil masing-masing.

5) Project Manager hanya dapat melihat proyek yang dibuatnya. 


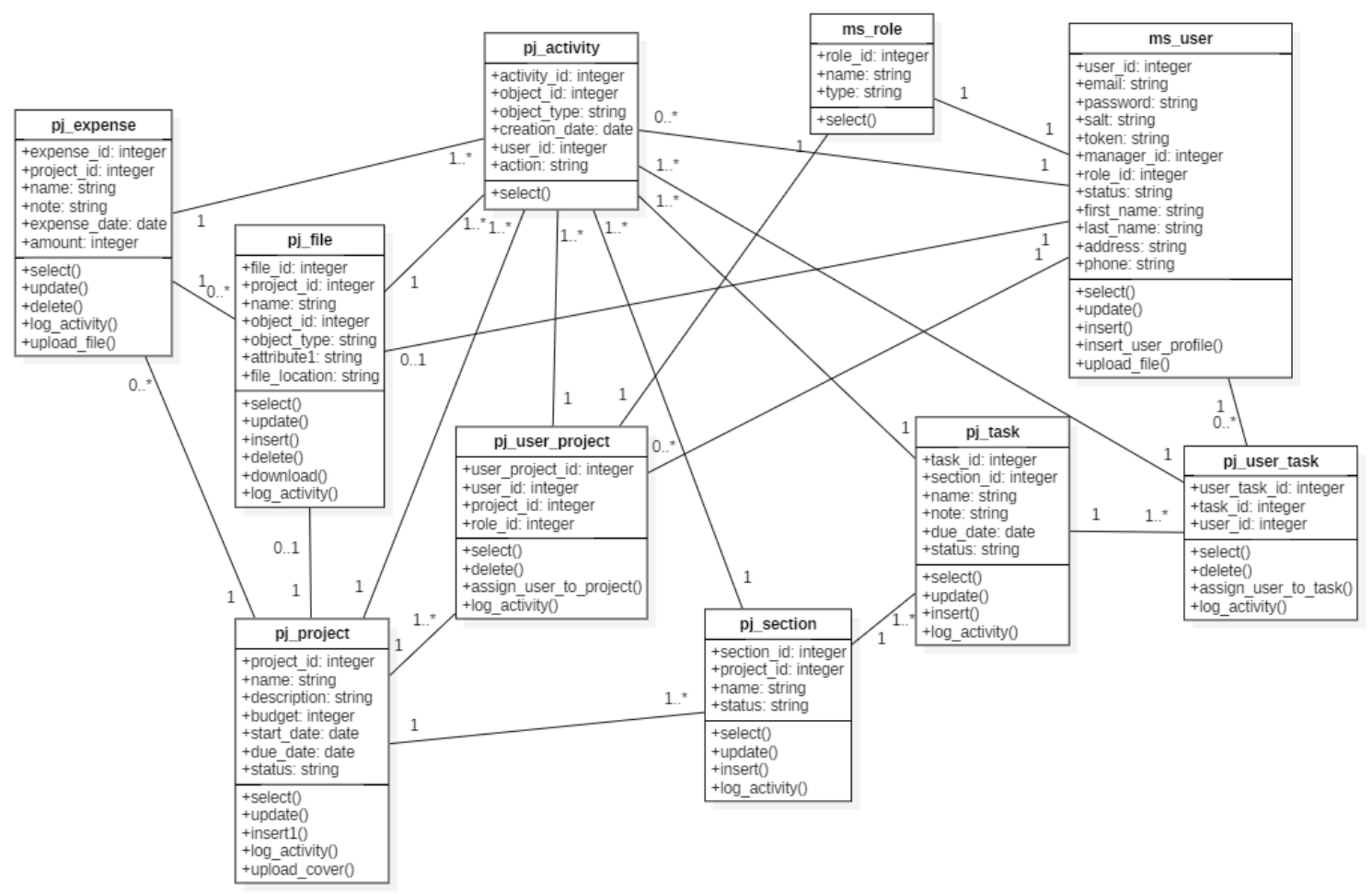

Gambar 2 Rancangan Class Diagram

6) Proyek yang dapat dilihat Project Leader dan Agent hanya yang ditugaskan kepadanya.

7) Setiap pengguna dapat mengelola kegiatan yang ditugaskan kepadanya.

8) Semua pengguna dapat mengelola data pengeluaran dalam proyek yang ditugaskan kepadanya.

9) Semua pengguna dapat mengelola berkas proyek dalam proyek yang ditugaskan kepadanya.

Semua pengguna dapat melihat laporan proyek dalam proyek yang ditugaskan kepadanya.

\subsection{Rancangan Use Case Diagram}

Diagram use case merupakan gambaran fungsional sistem yang melibatkan aktor untuk menampilkan fungsi apa saja yang dapat dilakukan oleh aktor dalam sistem. Gambaran diagram use case dapat dilihat pada Gambar 2.

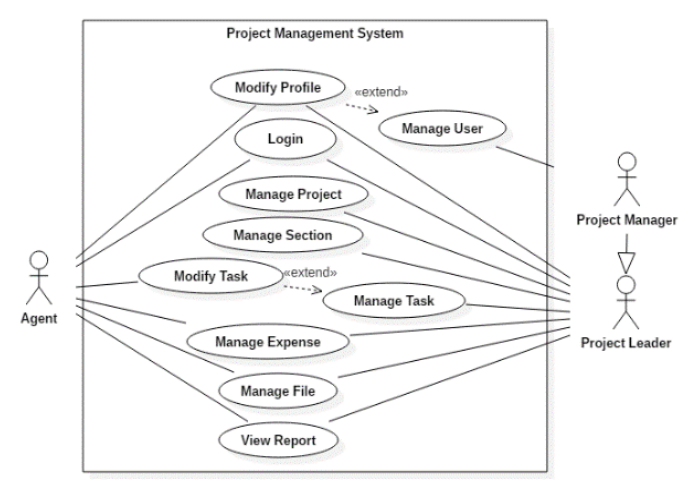

Gambar 3 Rancangan Use Case Diagram

\subsection{Rancangan Class Diagram}

Diagram kelas adalah diagram UML yang menggambarkan kelas-kelas dalam sebuah sistem dan hubungannya antara satu dengan yang lain, serta dimasukkan pula atribut dan operasi dari setiap kelas. Rancangan diagram kelas dapat dilihat pada Gambar 3.

\section{HASIL DAN PEMBAHASAN}

Hasil dari penelitian ini merupakan sebuah sistem informasi manajemen proyek berbasis kanban. Berikut tampilan antarmuka aplikasi yang terdiri dari lima belas tampilan antarmuka sistem dan lima tampilan laporan. Pada artikel ini hanya akan ditampilkan enam tampilan antarmuka utama dan empat tampilan laporan.

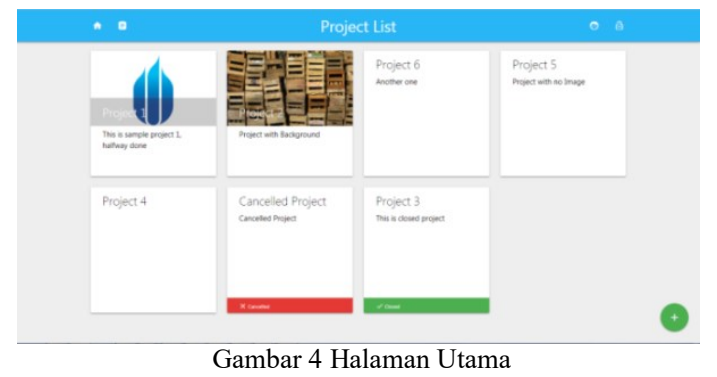

Gambar 4 menampilkan halaman utama dari sistem informasi manajemen proyek, dimana halaman tersebut menampilkan daftar proyek yang ada sesuai dengan tingkat wewenang pengguna, dimana manajer proyek dapat melihat semua proyek yang dibuat dan staf hanya dapat melihat proyek yang ditugaskan kepadanya. 
Terdapat juga navbar dimana berisi tautan untuk menu Home, Tasklist, profil, dan Logout. Pengguna dapat membuat proyek baru melalui tombol pada kanan bawah.

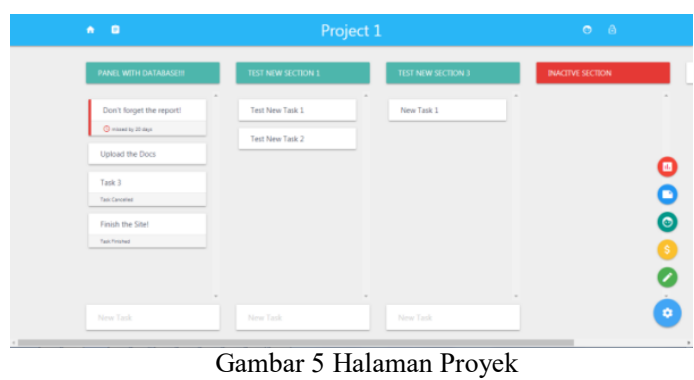

Gambar 5 menampilkan halaman proyek, dimana sistem menampilkan daftar bagian dan pekerjaan atau tugas yang ada di dalam proyek tersebut. Untuk menambahkan bagian atau tugas, cukup mengisi nama bagian atau tugas pada kolom New Section atau New Task, dan dapat dirubah dengan memilih bagian atau pekerjaan yang akan dirubah.

Terdapat juga menu pada bagian kanan bawah yang berisi menu Edit Project, Expense Information, Team Management, File Management, dan Report.

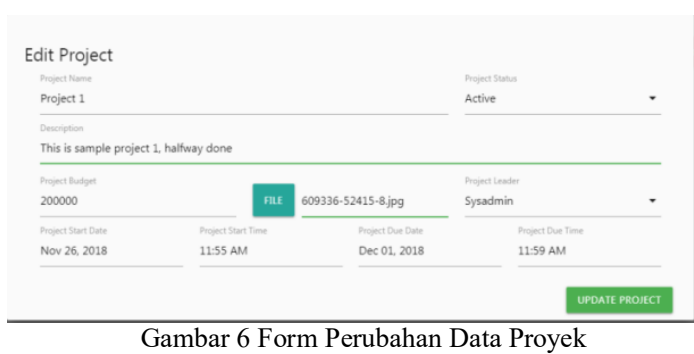

Gambar 6 menampilkan form Edit Project, dimana form yang sama juga digunakan pada saat pembuatan proyek baru. Dalam form tersebut, terdapat kolom nama proyek, deskripsi, status proyek, jumlah anggaran proyek, menu unggah gambar untuk latar proyek pada halaman utama, project leader, tanggal mulai, dan tanggal deadline proyek.

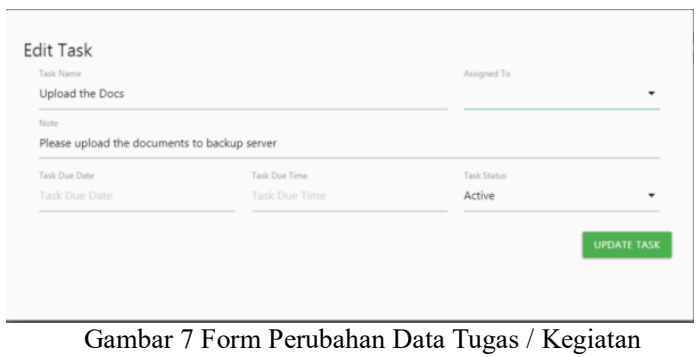

Gambar 7 menampilkan form Edit Task, dimana form tersebut digunakan untuk mengisi detil dari tugas yang sudah dibuat. Terdapat kolom nama kegiatan, staf yang ditugaskan, catatan, deadline tugas, dan status.

Gambar 8 menampilkan halaman manajemen pengeluaran (expenses), dimana berfungsi untuk mendata setiap pengeluaran yang terjadi untuk proyek tersebut. Setiap pengeluaran yang di data pada menu ini akan dihitung nilainya pada laporan.
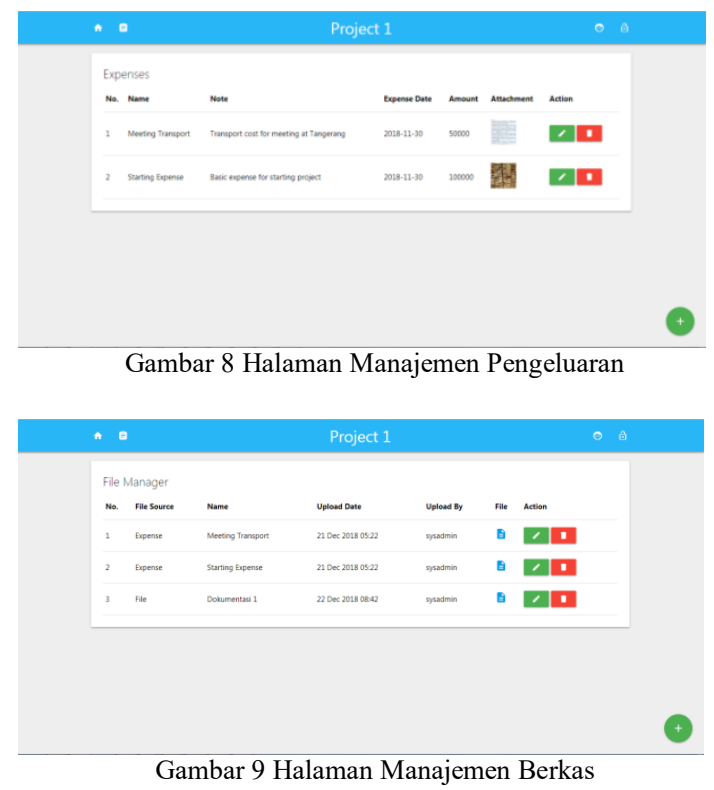

Gambar 9 menampilkan halaman manajemen berkas, dimana berfungsi untuk mengelola berkasberkas proyek, seperti surat-surat, foto, atau berkasberkas lainnya.

Gambar 10 menampilkan bentuk laporan proyek secara keseluruhan, dimana berisi data garis besar dari proyek tersebut dan kegiatannya. Laporan yang dihasilkan dapat tampilkan pada tab baru atau dapat diunduh langsung dalam format excel.

Gambar 11 menampilkan bentuk laporan pengeluaran proyek, dimana berisi data dari menu manajemen pengeluaran. Laporan yang dihasilkan dapat tampilkan pada tab baru atau dapat diunduh langsung dalam format excel.

Gambar 12 menampilkan bentuk laporan tugas atau kegiatan, yang berisi data tugas atau kegiatan yang lebih terperinci dibandingkan dengan laporan proyek. Laporan yang dihasilkan dapat tampilkan pada tab baru atau dapat diunduh langsung dalam format excel.

Gambar 13 menampilkan bentuk laporan performa pengguna, dimana berisi data garis besar capaian pengguna tersebut, dan data capaian

pengguna tersebut pada proyek terkait. Laporan yang dihasilkan dapat tampilkan pada tab baru atau dapat diunduh langsung dalam format excel. 
290 Jurnal Teknologi Informasi dan Ilmu Komputer (JTIIK), Vol. 7, No. 2, April 2020, hlm. 283-292

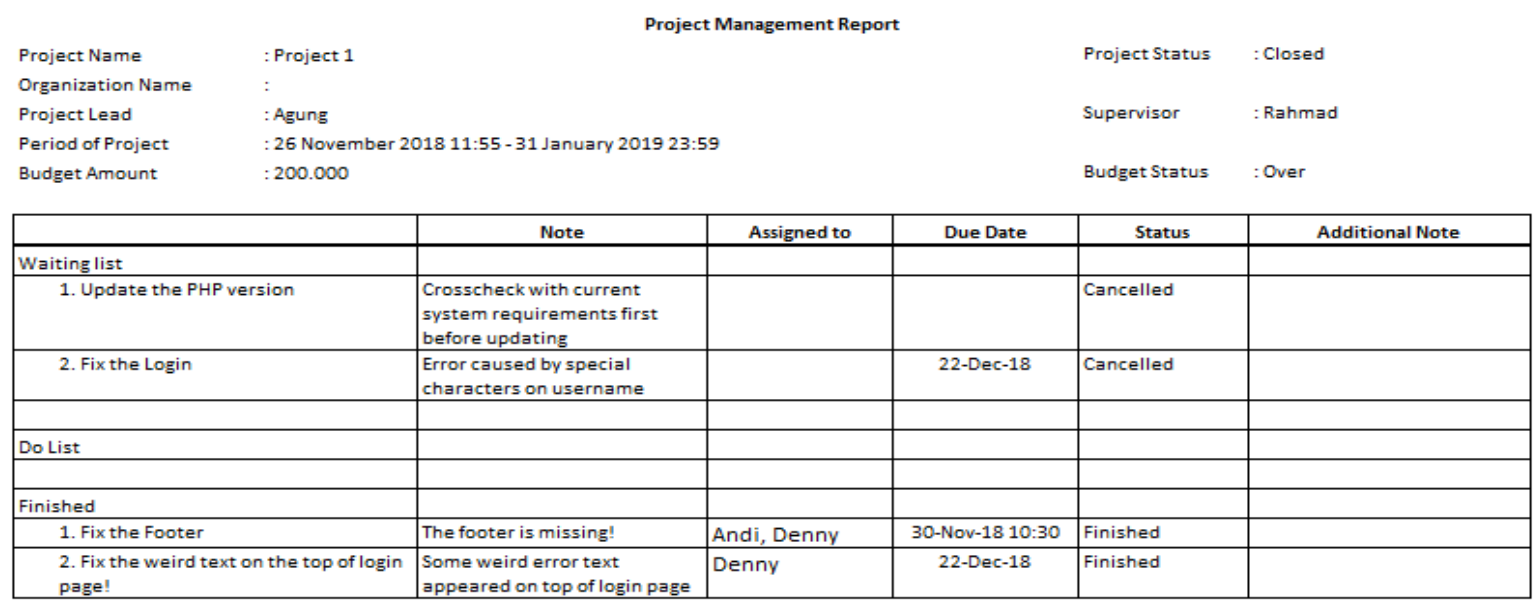

Project Note

$\begin{array}{lc}\text { Project Leader } & \text { 21 December } 2018 \\ \text { Supervisor }\end{array}$

(Agung)

Gambar 10 Tampilan Laporan Proyek
(Rahmad)

Project Expense Report

$\begin{array}{lll}\text { Project Name } & : \text { Project 1 } & \text { Project Status } \\ \text { Organization Name } & : & \text { Supervisor } \\ \text { Project Lead } & : \text { Agung } & \text { :Active } \\ \text { Report Period } & : 26 \text { November 2018-20 December } 2018 & \text { Budget Status } \\ \text { Budget Amount } & : 200,000 & : \text { Over }\end{array}$

Budget Amount $\quad \cdot 200,000 \quad$ Budget Status: Over

\begin{tabular}{|r|l|c|c|r|r|r|}
\hline No & \multicolumn{1}{|c|}{ Expense Name } & Expense Date & Receipt (Attachment) & \multicolumn{1}{c|}{ Amount } & \multicolumn{1}{c|}{ Balance } \\
\hline 1 & Meeting Transport & 30-Nov-18 & Document & 50,000 & 150,000 & \\
\hline 2 & Starting Expense & 30-Nov-18 & Document & 100,000 & 50,000 & \\
\hline 3 & Testing Kit & 18-Dec-18 & Document & $3,233,335$ & $-3,183,335$ & \\
\hline \multicolumn{2}{|r|}{ Total } & $3,383,335$ & \\
\hline
\end{tabular}

Project Leader

(Agung)

Gambar 11 Tampilan Laporan Pengeluaran
, 21 December 2018

Supervisor

(Rahmad)

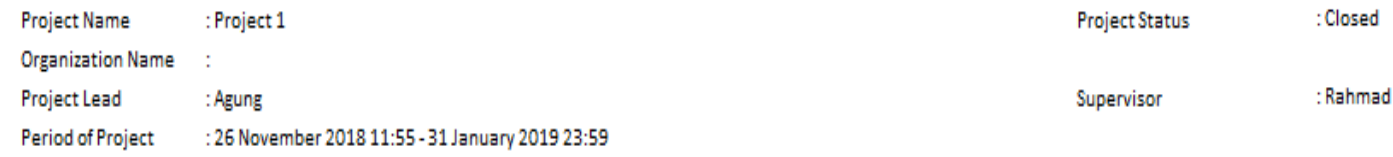

\begin{tabular}{|r|l|l|l|c|c|c|c|c|}
\hline No & \multicolumn{1}{|c|}{ Task } & \multicolumn{1}{c|}{ Note } & Assigned to & Due Date & Finished Date & Time Difference & \multicolumn{1}{c|}{ Status } & \multicolumn{1}{c|}{ Additional Note } \\
\hline 1 & Fix the Footer & The footer is missing! & Andi, Denny & 30-Nov-18 10:30 & 30-Nov-18 11:00 & 30 Minutes & Over & \\
\hline 2 & $\begin{array}{l}\text { Fix the weird text on the top of } \\
\text { login page! }\end{array}$ & $\begin{array}{l}\text { Some weird error text } \\
\text { appeared on top of login } \\
\text { page }\end{array}$ & Denny & $22-$ Dec-18 & 23-Dec-18 & 1 Day & Over & \\
\hline
\end{tabular}




\begin{tabular}{|c|c|c|c|c|c|c|}
\hline \multicolumn{7}{|c|}{ User Performance Report } \\
\hline Name & :Agung & & & & Status & : Active \\
\hline Email & :Agung & & & & Phone & : 081297887254 \\
\hline Address & : Meruya Ilir Raya & & & & Manager & : Rahmad \\
\hline Project & : Project 1 & & & & Role & : Agent \\
\hline \multicolumn{7}{|c|}{ Overall Performance (All Project) } \\
\hline Number of Project & $\begin{array}{c}\text { Number of Task } \\
\text { Taken }\end{array}$ & $\begin{array}{c}\text { Number of Task } \\
\text { Completed }\end{array}$ & $\begin{array}{c}\text { Number of Task On } \\
\text { Time }\end{array}$ & Number of Task Over & $\begin{array}{c}\text { Task On Time } \\
\text { Percentage }\end{array}$ & \\
\hline 1 & 4 & 4 & 1 & 3 & $25 \%$ & \\
\hline
\end{tabular}

\begin{tabular}{|c|c|c|c|c|c|c|}
\hline No & Task & Due Date & Finished Date & Time Difference & Status & Additional Note \\
\hline 1 & Update the PHP version & 22-Dec-18 & 23-Dec-18 & 1 Day & Over & \\
\hline 2 & Fix the Login & 22-Dec-18 & 22-Dec-18 & 1 Day & On Time & \\
\hline 3 & Fix the Footer & 30-Nov-18 10:30 & 30-Nov-18 11:00 & 30 Minutes & Over & \\
\hline 4 & Fix the weird text on the top of & $22-$ Dec-18 & 23-Dec-18 & 1 Day & Over & \\
\hline
\end{tabular}

Note:

Project Leader

(Agung)
,21 December 2018

Supervisor

(Rahmad)

Gambar 13 Tampilan Laporan Performa Perorangan

\section{KESIMPULAN}

Pengelolaan proyek pada PT XYZ saat ini masih dilakukan dengan menggunakan perangkat lunak pengolah data seperti Microsoft Excel, dimana hal ini menjadikan proses pengelolaan proyek terpusat pada satu orang, mempersulit dalam berbagi informasi, dan tidak terstrukturnya berkas antara data satu proyek dengan proyek yang lain. Agar pengelolaan proyek dapat lebih tersturktur, efisien, dan mudah, maka perlu dibangun sebuah sistem manajemen proyek untuk mewadahi setiap proyek.

Sistem manajemen proyek yang dibangun mengadopsi tampilan yang menyerupai Kanban, dimana setiap kegiatan dikelompokkan berdasarkan pada garis besar kegiatan. Dengan pengelolaan kegiatan yang dapat dilakukan oleh agent atau staf proyek sehingga setiap kegiatan dapat langsung diperarui kapan saja. Selain itu, dengan menu manajemen pengeluaran manajer proyek dapat memantau pengeluaran proyek dengan lebih mudah dan dapat mendeteksi pengeluaran yang tidak diperlukan. Menu manajemen berkas juga membantu antar anggota tim dalam berbagi berkas, sehingga tidak perlu lagi meminta berkas secara langsung kepada anggota tim lain.

Dengan demikian, sistem manajemen proyek berbasis kanban yang dikembangkan telah dapat menyelesaikan permasalahan tidak adanya sistem manajemen proyek pada PT. XYZ dan juga menyelesaikan permasalahan sulitnya berbagi informasi dan juga membantu manajer proyek dalam pengelolaan proyek dari segi manajemen sumber daya, waktu, dan biaya.
Penelitian ini dibuat berdasarkan data-data yang diperoleh dalam jangka waktu, kondisi, dan pada lokasi tertentu, sehingga terdapat kemungkinan penelitian ini tidak relevan ketika digunakan pada waktu, kondisi, dan lokasi yang berbeda, sehingga disarankan untuk disesuaikan dengan kondisi yang ada.

\section{DAFTAR PUSTAKA}

A Guide to the Project Management Body of Knowledge (5th ed.). (2013). Newtown Square: Project Management Institute, Inc.

AL-ZEWAIRI, M., BILTAWI, M., ETAIWI, W., \& SHAOUT, A. (2000). Agile Software Development Methodologies: Survey of Surveys. Journal of Computer and Communications, 5, 74-97.

GRAHAM, K. (2017). TechMatters: Getting on the "Kanban"-wagon: Using KanbanFlow for Time and Project Management.

HOUTI, M., EL ABBADI, L., \& ABOUABDELLAH, A. (2017). E-Kanban the new generation of traditional Kanban system, and the impact of its implementation in the enterprise.

IZANG, A., IHESIULO, C., \& OKAFOR, C. (2016). A Web-Based Project Management System. International Journal of Advanced Research in Computer Science and Software Engineering, 6(4), 2277.

KALE, S., SHEWALE, A., SARANG, P., PAWAR, P., \& Sadruddin, S. (2017). Project Management System (PMS). (C) 2017 IJEDR |, 5(2). 
LANDICHO, J. (2018, 9). A web-based geographical project monitoring and information system for the road and highways. Journal of Electrical Systems and Information Technology, 5(2), 252-261.

MAHMOUDI, A., \& FEYLIZADEH, M. (2017). A mathematical model for crashing projects by considering time, cost, quality and risk. Journal of Project Management, 2, 27-36.

PADMA ARIANIE, G., \& BUDI PUSPITASARI, N. (2017, 9 22). Perencanaan Manajemen Proyek Dalam Meningkatkan Efisiensi Dan Efektifitas Sumber Daya Perusahaan (Studi Kasus : Qiscus Pte Ltd).J@ti Undip : Jurnal Teknik Industri, 12(3), 189.

PUAR, Z., \& SIREGAR, M. (2017, 2 10). Rancangan Sistem Elektronik Kanban Untuk Meningkatkan Efektivitas Produksi Just In Time. Jurnal Manajemen Industri Dan Logistik, 1(1), 86.

SETIAWAN, H., \& KHAIRUZZAMAN, M. (2017, 12 24). Perancangan Sistem Informasi Manajemen Proyek: Sistem Informasi Kontraktor. Jurnal Khatulistiwa Informatika, 5(2). 